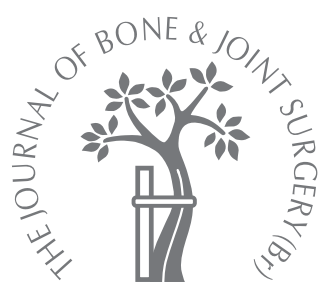

M. B. S. Brewster, M. Gupta, G. T. R. Pattison, I. D. Dunn-van der Ploeg

From University Hospitals Coventry and Warwickshire, Coventry, England

\title{
Ponseti casting
}

\author{
A NEW SOFT OPTION
}

We have modified the Ponseti casting technique by using a below-knee Softcast instead of an above-knee plaster of Paris cast. Treatment was initiated as soon as possible after birth and the Pirani score was recorded at each visit. Following the manipulation techniques of Ponseti, a below-knee Softcast was applied directly over a stockinette for a snug fit and particular attention was paid to creating a deep groove above the heel to prevent slippage. If necessary, a percutaneous Achilles tenotomy was performed and casting continued until the child was fitted with Denis Browne abduction boots.

Between April 2003 and May 2007 we treated 51 consecutive babies with 80 idiopathic club feet with a mean age at presentation of 4.5 weeks (4 days to 62 weeks). The initial mean Pirani score was 5.5 (3 to 6). It took a mean of 8.5 weeks (4 to 53) of weekly manipulation and casting to reach the stage of percutaneous Achilles tenotomy. A total of 20 feet $(25 \%)$ did not require a tenotomy and for the $\mathbf{6 0}$ that did, the mean Pirani score at time of operation was 2.5 (0.5 to 3). Denis Browne boots were applied at a mean of 10 weeks (4 to 56) after presentation. The mean time from tenotomy to boots was 3.3 weeks (2 to 10). We experienced one case of cast-slippage during a period of non-attendance, which prolonged the casting process. One case of prolonged casting required repeated tenotomy, and three feet required repeated tenotomy and casting after relapsing while in Denis Browne boots.

We believe the use of a below-knee Softcast in conjunction with Ponseti manipulation techniques shows promising initial results which are comparable to those using above-knee plaster of Paris casts.

M. B. S. Brewster, MBChB, MRCSEng, Specialist Registrar in Trauma and Orthopaedics G. T. R. Pattison, MBBS, FRCSEd(Tr \& Orth), Consultant Paediatric Orthopaedic Surgeon

I. D. Dunn-van der Ploeg, Artsexamen, FRCS, FRCS

(Trauma and Orthopaedics), Consultant Paediatric

Orthopaedic Surgeon

University Hospitals Coventry and Warwickshire, Clifford Bridge Road, Coventry CV2 2DX, UK.

M. Gupta, MBBS, MRCSEdin, Specialist Registrar in Trauma and Orthopaedics

City Hospital, Dudley Road, Birmingham B18 70H, UK.

Correspondence should be sent to Mr M. B. S. Brewster; e-mail: markbrewster@doctors.org.uk

(C)2008 British Editorial Society of Bone and Joint Surgery doi:10.1302/0301-620X.90B11. $20629 \$ 2.00$

$J$ Bone Joint Surg [Br] 2008;90-B:1512-15.

Received 17 December 2007;

Accepted after revision 6 June 2008
The Ponseti technique ${ }^{1}$ is increasingly popular in the treatment of congenital talipes equinovarus. However, his method of serial manipulation and above-knee plaster of Paris casting causes some practical difficulties. Above-knee casts can make perineal hygiene more difficult, especially in bilateral cases and the removal of casts can be distressing for the child and parents. ${ }^{2}$ The theoretical disadvantages of aboveknee casts include the immobilisation of rapidly growing bones and joints. ${ }^{3,4}$

The developments in casting materials have allowed for a moulded synthetic below-knee cast, which is preferred by patients to a plaster of Paris cast. ${ }^{2}$ We report our early experience with this modification of the Ponseti technique.

\section{Patients and Methods}

The study group consisted of 51 consecutive babies ( 80 feet). There were 37 boys and 14 girls with a mean age at presentation of 4.5 weeks (4 days to 62 weeks).
The modified casting technique has been used in our hospital since April 2003. We excluded children with previous failed treatment in other centres and those with neuromuscular or syndromic disorders. Treatment was started as soon as possible after birth and the feet were evaluated throughout treatment using the Pirani score. ${ }^{5,6}$

Manipulation progressively corrects the deformities through elevation of the first ray, abduction of the foot around the talar neck and dorsiflexion of the ankle (Fig. 1). A small piece of Granuflex (ConvaTec, Bristol-Myers Squibb, New York, New York) is applied over the talar head to prevent skin maceration between wrinkles created by abduction. The below-knee Softcast (3M Health Care, St Paul, Minnesota) is applied directly over a stockinette, without padding thereby obtaining a snug fit. As the Softcast is being applied, particular attention is paid to the formation of a groove above the heel, as suggested by Ponseti and Campos ${ }^{1}$ to prevent slippage of the cast. It is also carefully 


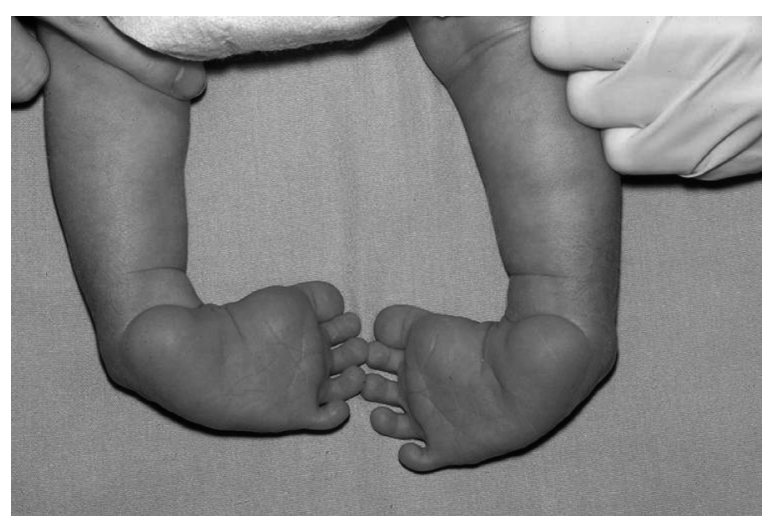

Fig. 1a
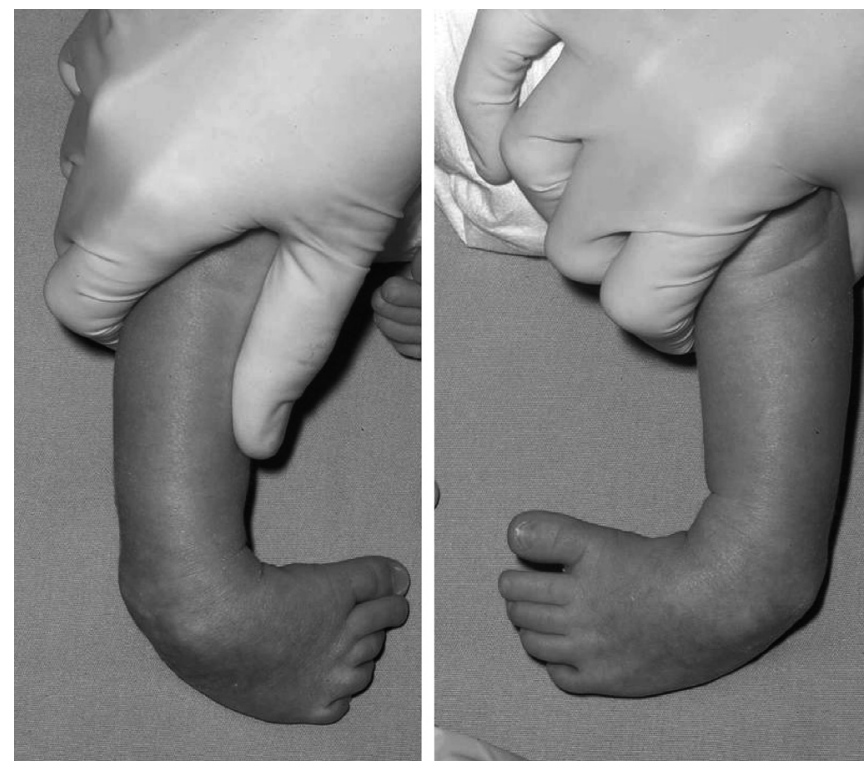

Fig. 1b

a) Photograph showing plantar view of feet pre-treatment and b) dorsal view of feet pre-treatment.

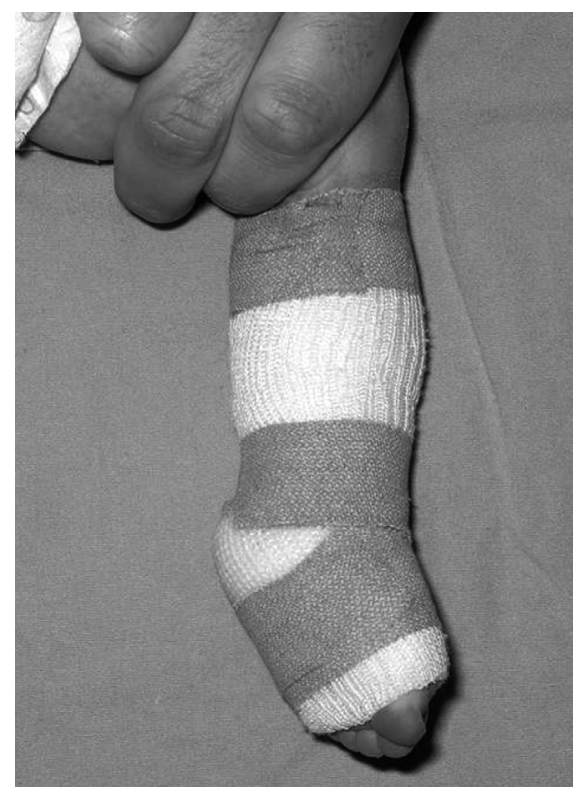

Fig. 2

Photograph showing below-knee cast.

moulded underneath the first ray, elevating the first metatarsal head and stretching the plantar structures. The foot is held in the corrected position until the material has set and the cast is completed with application of Elastoplast taping to the proximal and distal ends (Fig. 2).

The casting is repeated weekly with the Pirani score documented on each occasion. Achilles tenotomy is considered when the forefoot is fully corrected and equinus persists.
The time to this stage is documented. The tenotomy is carried out percutaneously under local anaesthetic in the operating theatre, usually within seven to 14 days depending on the availability of theatre time. Post-operatively, a belowknee cast is applied for about three weeks.

All feet were followed to the application of Denis Browne abduction boots (M. J. Markell Shoe Co., Yonkers, New York) and beyond. Any complications were noted and the outcome measure was a fully corrected foot which fitted comfortably into the Denis Browne boots.

We defined relapses as those feet which required further casting or repeat tenotomy and failures as those which required more extensive surgery.

\section{Results}

The initial mean Pirani score was 5.5 (3 to 6). It took a mean of 8.5 weeks (4 to 53) of weekly manipulation and casting to reach the stage of percutaneous Achilles tenotomy. A total of 20 feet $(25 \%)$ did not require tenotomy and for the 60 that did, the mean score at operation was 2.5 (0.5 to 3.0). Denis Browne boots were applied after a mean of 10 weeks ( 4 to 56) following initial presentation. The mean time from tenotomy to boots was 3.3 weeks (2 to 10 ). The mean Pirani score at presentation was 5.8 (4 to 6) for feet requiring a tenotomy and five (3 to 6) for those that did not. The mean follow-up was 27 months (6 to 55).

Table I shows that in the majority of categories our results fall mid-range when compared with other studies. ${ }^{7-15}$ The theoretical advantage of allowing knee movement to stretch the gastrocnemius complex has not produced lower tenotomy rates but definitive conclusions on this aspect would need to be assessed with longer follow-up and a 
Table I. Results of current study in comparison with previously published studies of the Ponseti technique

\begin{tabular}{|c|c|c|c|c|c|c|c|c|}
\hline & $\begin{array}{l}\text { Number of } \\
\text { babies }\end{array}$ & $\begin{array}{l}\text { Number of } \\
\text { feet }\end{array}$ & $\begin{array}{l}\text { Mean initial } \\
\text { age (weeks) }\end{array}$ & $\begin{array}{l}\text { Mean weeks } \\
\text { to tenotomy }\end{array}$ & $\begin{array}{l}\text { Mean total } \\
\text { weeks in cast }\end{array}$ & $\begin{array}{l}\text { Patients without } \\
\text { tenotomy }(\%)\end{array}$ & Follow-up & $\begin{array}{l}\text { Number of } \\
\text { relapses (\%) }\end{array}$ \\
\hline Current study & 51 & 80 & 4.5 & 8.5 & 10 & 25 & 27 mths & 6.25 \\
\hline Laaveg and Ponseti ${ }^{7}$ & 70 & 104 & 6.9 & - & 8.6 & 12.5 & 18.7 yrs & 23 \\
\hline Radler et al ${ }^{8}$ & 37 & 59 & $<3$ & - & 11.4 & 0 & - & 2 \\
\hline Bor et $\mathrm{al}^{9}$ & 23 & 36 & $<8$ & 6 & 9 & 0 & - & 14 \\
\hline Segev et $\mathrm{al}^{10}$ & 32 & 48 & 1.3 & 10 & 13 & 2 & 29.2 mths & 6 \\
\hline Changulani et al ${ }^{11}$ & 66 & 100 & 12 & - & - & 11 & 18 mths & 31 \\
\hline Colburn and Williams ${ }^{12}$ & 14 & 24 & 1.3 & - & 7.8 & 12.5 & 22.9 mths & 17 \\
\hline Docker et $\mathrm{al}^{13}$ & & 62 & - & - & - & 31 & 17 mths & 25 \\
\hline Dyer and Davis ${ }^{5}$ & 47 & 70 & - & 5.3 & - & 40 & - & - \\
\hline Shack and Eastwood ${ }^{14}$ & 24 & 40 & 4.3 & 5 & 8 & 37.5 & 20.3 mths & 7.5 \\
\hline Abdelgawad et al ${ }^{15}$ & 89 & 137 & 6.6 & 5.5 & - & 23.6 & 24 mths & 13 \\
\hline
\end{tabular}

* total time in casts correlates with time to application of Denis Browne boots

comparison of relapse rates in those without tenotomy in the different groups. Our relapse rate is comparable with studies of similar follow-up times.

One baby was 62 weeks of age, at initial casting. His presentation was delayed as the family had only recently moved to England. There had been no previous treatment but he did not require tenotomy and was wearing Denis Browne boots after three weeks of casting. Four babies (five feet) relapsed during treatment. One foot failed to progress to boots and required repeat tenotomy and casting in order to tolerate them. Two babies (three feet) relapsed while in Denis Browne boots. Compliance was an issue in both cases. They underwent recasting and repeat tenotomy without further surgery but they required an extra nine and 21 weeks in casts, respectively.

One foot which had repeated relapses had problems with cast slippage and parental compliance. The Pirani score at presentation was six and, following uneventful treatment, he was a week away from tenotomy but did not attend his follow-up appointment. He presented two weeks later with a slipped cast. A deformity worse than at original presentation developed and, although open surgery was offered, his mother was keen to persist with casting. Surprisingly, the foot responded to casting after a total of 56 weeks.

Since this case, there were no cases of cast slippage and no complications other than minor skin irritation if the cast had been applied slightly too high behind the knee. Such irritation is treated with a small disc of Granuflex. No patients were lost to follow-up.

\section{Discussion}

The Ponseti technique is reliable, with good long-term results. $^{7-16}$

Ponseti ${ }^{17}$ commented that a mistake in using his technique was to use below-knee plasters because longer plasters are needed to prevent the ankle and talus from rotating. As the foot must be held abducted under the talus, this must not rotate otherwise the correction is lost. Our theory was that we could prevent a large amount of rotation of the
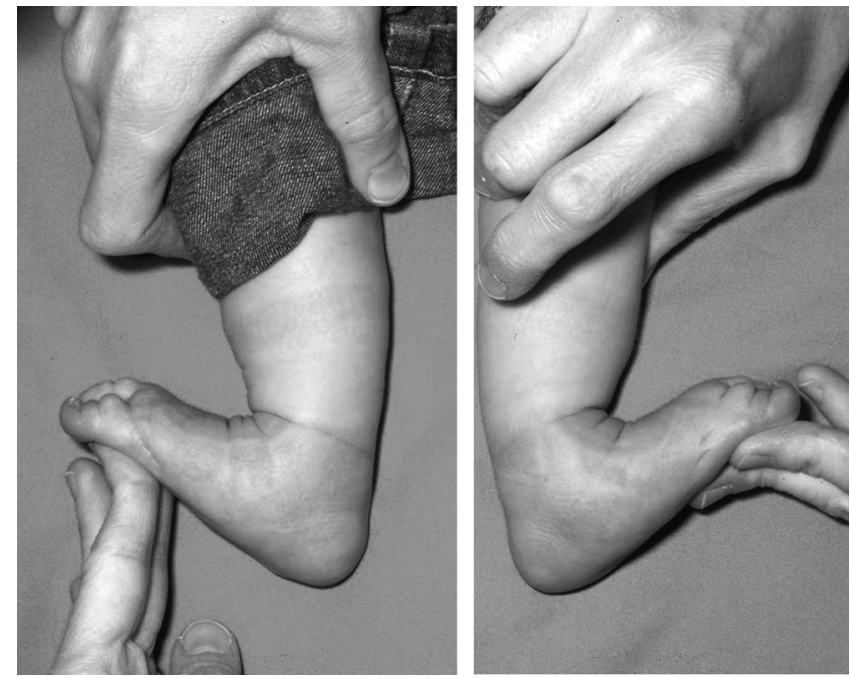

Fig. 3

Photograph showing treated feet in dorsiflexion.

talus with a very close fitting cast. We have had only one case of slippage and perineal care is uncomplicated.

The standard removal techniques for plaster of Paris casts include soaking for up to 60 minutes and unwrapping the plasters or using a plaster saw or knife which can be dangerous and distressing to the child and parents. Softcast requires unwinding alone. There are also theoretical concerns about immobilisation of the knee during the growth and development of long bones and adjacent joints. Experimental evidence in rats suggests that short-term immobilisation causes cancellous bone loss in regions undergoing high turnover and/or modelling. ${ }^{3}$ Another study ${ }^{4}$ examined the effects of immobilisation on fetal bone development. In newborn babies with congenital neuromuscular diseases of intrauterine onset it was suggested that intrauterine immobilisation leads to problems with bone quality and osteoporosis, along with failure of proper radial growth and development. Osteopenia after immobilisation in above- 
knee casts was seen by Lourenco and Morcuende ${ }^{18}$ in five of 17 children. These findings, however, were resolved within a few months of cast removal. A below-knee cast allows natural movement; stretching and growth of the quadriceps, hamstrings, gastrocnemius muscle complex and the tendo Achillis.

The Pirani score can only compare the severity of congenital talipes equinovarus. There is no scoring system for the weightbearing plantar grade foot once the patient is in Denis Browne boots or discharged. The only measure at this stage is the ability of the child to bear weight on a painless, flexible, plantar grade foot that has a reasonable rotational profile and good abduction and dorsiflexion (Fig. 3). This result, along with the lack of extensive surgery (excluding Achilles tenotomy) is deemed a successful outcome for casting techniques.

Our series has moderate numbers but only a short follow-up. Laaveg and Ponseti ${ }^{7}$ discovered that the majority of the relapses occur three years after completion of treatment and we aim to publish our five-year follow-up to confirm the success of our 'new soft option'.

In conclusion, we believe that a below-knee Softcast in conjunction with Ponseti manipulation techniques shows promising initial results which are comparable to those using an above-knee plaster of Paris cast.

Although the authors have not received and will not receive benefits for personal or professional use from a commercial party related directly or indirectly to the subject of this manuscript, benefits in the form of products have been received but are used solely for non-profit educational purposes within this institution.

\section{References}

1. Ponseti IV, Campos J. Observations on pathogenesis and treatment of congenital clubfoot. Clin Orthop 1972;84:50-60.

2. Coss HS, Hennrikus WL. Parent satisfaction comparing two bandage materials used during serial casting in infants. Foot Ankle Int 1996;17:483-6.
3. Shen V, Liang XG, Birchman R, et al. Short-term immobilization-induced cancellous bone loss is limited to regions undergoing high turnover and/or modeling in mature rats. Bone 1997;21:71-8.

4. Rodríguez JI, Palacios J, García-Alix A, Pastor I, Paniagua R. Effects of immobilization on fetal bone development: a morphometric study in newborns with congenital neuromuscular diseases with intrauterine onset. Calcif Tissue Int 1988;43:335-9.

5. Dyer PJ, Davis B. The role of the Pirani scoring system in the management of club foot by the Ponseti method. J Bone Joint Surg [Br] 2006;88-B:1082-4.

6. Ponseti IV, et al. Clubfoot Ponseti management: Pirani severity scoring. www.global-help.org (date last accessed 4 December 2007).

7. Laaveg SJ, Ponseti IV. Long-term results of treatment of congenital club foot. J Bone Joint Surg [Am] 1980;62-A:23-31.

8. Radler C, Suda R, Manner HM, Grill F. Early results of the Ponseti method for the treatment of idiopathic clubfoot. Z Orthop Ihre Grenzgeb 2006;14:80-6 (in German).

9. Bor N, Herzenberg JE, Frick SL. Ponseti management of clubfoot in older infants. Clin Orthop 2006;444:224-8.

10. Segev E, Keret D, Lokiec F, et al. Early experience with the Ponseti method for the treatment of congenital idiopathic clubfoot. Isr Med Assoc J 2005;7:307-10.

11. Changulani M, Garg NK, Rakagopal TS, et al. Treatment of idiopathic club foot using Ponseti method initial experience. J Bone Joint Surg [Br] 2006;88-B:1385-7.

12. Colburn M, Williams $\mathbf{M}$. Evaluation of the treatment of idiopathic clubfoot by using the Ponseti method. J Foot Ankle Surg 2003;42:259-67.

13. Docker CE, Lewthwaite S, Kiely NT. Ponseti treatment in the management of clubfoot deformity: a continuing role for paediatric orthopaedic services in secondary care centres. Ann R Coll Surg Eng/2007;89:510-12.

14. Shack N, Eastwood DM. Early results of a physiotherapist-delivered Ponseti service for the management of idiopathic congenital talipes equinovarus foot deformity. J Bone Joint Surg [Br]2006;88-B:1085-9.

15. Abdelgawad AA, Lehman WB, van Bosse HJ, Scher DM, Sala DA. Treatment of idiopathic clubfoot using the Ponseti method: minimum 2-year follow-up. J Pediatr Orthop B 2007;16:98-105

16. Morcuende JA, Dolan LA, Dietz FR, Ponseti IV. Radical reduction in the rate of extensive corrective survery for clubfoot using the Ponseti method. Pediatrics 2004;113:376-80.

17. Ponseti IV. Treatment of congenital clubfoot. University of lowa Children's Hospital/ Healthcare website. March 1996 (Revised May 2004). http://www.uihealthcare.com/ topics/medicaldepartments/orthopaedics/clubfeet/forproviders/index.html (date last accessed 4 December 2007).

18. Lourenco AF, Morcuende JA. Correction of neglected idiopathic club foot by the Ponseti method. J Bone Joint Surg [Br] 2007;89-B:378-81. 